\title{
Long-time series of racial maps with a time-invariant legend
}

\author{
Anna Dmowska ${ }^{\text {ab }}$ and Tomasz F. Stepinski ${ }^{\mathrm{a}}$ \\ aSpace Informatics Lab, Department of Geography and GIS, University of Cincinnati, USA; \\ ${ }^{\mathrm{b}}$ Institute of Geoecology and Geoinformation, Adam Mickiewicz University, Poznan, Poland
}

\section{ARTICLE HISTORY}

Compiled October 17, 2021

\begin{abstract}
Although there is significant literature on quantifying racial segregation in the US cities using numerical metrics, there is a lack of comprehensive studies that chronicle, over a long time, the evolution of the spatial distribution of racial groups from which segregation had arisen. Mapping multi-decades changes in racial geography of major US cities provide information on the evolution of spatial configuration of racial divides and, ultimately, provides insight into social processes that led to presently observed segregation. To fill this gap, we have developed and made freely available a set of GIS-compatible time series of racial maps featuring a time-invariant categorization of racial groups. These GIS-based maps cover 63 major cities in the US at the resolution of the census tract. Maps go back as far as the availability of the census allows, in some cases as far back as 1910. To make such map series possible, we needed to overcome changing categorizations of racial groups in past censuses and changes in the census tracts' boundaries. The paper explains our methodology and presents, as an example of temporal mapping, the case study for Cook County, IL (which contains the core of the present-day Chicago).
\end{abstract}

\section{KEYWORDS}

evolution of racial geography; racial segregation, racial diversity 


\section{Introduction}

The social, economic, and political structure of US society has been hugely influenced by the waves of migration. From 1890 to present, three periods had a significant impact on the racial structure of the US population: 1) 1890-1910 - international migration dominated by Europeans (especially from the south and central-east Europe); 2) 19161970 - Great Migration (the movement of Blacks from rural Southern US to the urban Northeast, Midwest and West regions of the US); 3) from the late 1960s to present migration from Asia and Latin America. These waves of migration have shaped the racial composition of the US major cities. The Great Migration significantly changed the spatial distribution of the Blacks population in the US, therefore changing the racial composition of major US cities from predominantly White to bi-racial (with a significant share of Blacks population), and finally to multi-racial (Iceland 2004).

Chronicling temporal changes in racial geography would greatly improve our understanding of how we get to the present situation characterized by significant racial segregation at the urban level. It also would provide material for testing theories of residential, racial segregation. Because these waves of migration affected multiple aspects of the US society, there is a significant body of literature capturing the changes in the racial composition, diversity, and segregation of the US major cities. However, the great majority of this literature is not map-based. It also does not address changing racial classifications, and thus covers only relatively short periods of time during which classification remains fixed.

Of the three components of the racial distribution, the quantification of composition and diversity is quite straightforward (Iceland et al. 2002), but the quantification of segregation is not. The level of segregation corresponds to the degree of spatial clumping of same-race inhabitants. Such clumping is readily visible on the racial map, but quantification of clumping, which involves reducing all the complexity of clumps observed in the map into a single number, can be done in multiple ways, none of which reflects unequivocally what is seen on the map. Therefore, it makes sense to chronicle racial distributions in terms of racial maps so we can see them in their full complexity. If needed, composition, as well as diversity and segregation metrics can 
be calculated from a GIS-based map to provide a numerical description. Contrarily, if racial distributions are chronicled only in terms of the metrics, there is no opportunity to know their spatial configuration and temporal changes to this configuration.

This notwithstanding, a large body of existing literature focuses on designing and calculating metrics of segregation. For the methodological review of different approaches to segregation metrics see Yao et al. (2018), and for implementation of many of these metrics see Hong et al. (2014). Discussing these methods is outside the scope of this paper. Most of the multi-city surveys Massey and Denton (1987), Iceland et al. (2002), Iceland (2004), Farrell (2008), Fischer (2003), Fischer et al. (2004), Logan et al. (2004), Parisi et al. (2011), Fowler et al. (2016), Ellis et al. (2018), Bellman et al. (2018) of racial segregation in the US and its change from one census to another has been done using segregation metrics, and in particular, using the Theil index $H$ of segregation Theil and Finizza (1971). In these studies chronicling temporal changes in racial segregation is tantamount to comparing magnitudes of segregation metrics. This gives bare minimum information about the trend of segregation but provides no insight into the spatial dynamics of the process.

There has been a long tradition among historical geographers and urban sociologists to map demographic data to study residential patterns in US cities (Du Bois 1899 , Radford 1976, Rabinowitz et al. 1978, Groves and Muller 1975, Gregory and Healey 2007). Du Bois (1899) mapped every Black residence, church, and business in the city's Seventh Ward, recording occupational and family structure to identify Philadelphia Blacks' sociologically relevant social issues. Between 1920-1934, R.Park and E.Burgess and their students completed three projects aiming at producing the maps for Chicago (Park and Burgess 2019, Burgess 2015, Owens 2012). Two of those projects delineated "neighborhoods." The first project delineated 75 distinct "community areas" for Chicago (Palmer 1929). The delineation of the community areas provided specific enough boundaries to collect data for the sociological research, including racial distribution. The examples of such maps are provided by the University of Chicago Library's Map Collection (https://www.lib.uchicago.edu/e/collections/maps/chisoc/). The second project delineated Chicago into 499 tracts in 1920 and 935 census tracts for 1930 and onwards. The data were published in three volumes of Census Data of 
the City of Chicago $(1920,1930,1934)$. These maps are provided as Social Science Research Committee Maps by the University of Chicago Library's Map Collection (https://www.lib.uchicago.edu/e/collections/maps/ssrc/).

However, as we have already mentioned, the focus shifted away from mapping and towards segregation metrics. Only in the last decade, mapping racial segregation started to appear again. All mapping works had to address two issues. (a) The race data is available only in an aggregated form. In the GIS terms, the data is in the vector (shapefile) format, with the US Census aggregated areas as features which attributes are numbers of people of different race categories inhabiting the feature. (b) Features (for example, census tracts) are not necessarily mono-racial. There are three ways to produce a single map of racial distribution from aggregated data, feature classification, one-dot-per-person mapping, and racial landscape. The first approach (Bader and Warkentien 2016, Holloway et al. 2012, Wright et al. 2014, Fasenfest et al. 2004, Clark et al. 2015 classifies each feature into one of predefined "neighborhood types" resulting in a map that shows a distribution of neighborhood types. Some of these types are practically mono-racial (segregated), but some are bi-racial (somewhat integrated), and few are multi-racial (integrated). A temporal change is expressed in terms of neighborhood transitions from one type to another. If, on balance, neighborhoods transition into more integrated types the segregation is said to be decreasing. The advantage of such assessment over the segregation metric assessment is that it provides some insight into the spatial dynamics of the process.

One-dot-per-person racial map (Kimerling 2009, Roth|2010, Dmowska and Stepinski 2019)1 is constructed by placing a number of dots equal to the number of inhabitants inside each feature. Dots are placed at random coordinates inside the feature and are color-coded by racial group. This method produces a good approximation to the spatial distribution of racial groups, especially if small aggregated areas (census blocks) are used, but it is difficult to quantify segregation from a one-dot-per-person map. In the racial landscape method (Dmowska et al. 2019) a vector census data is transformed to a raster (grid) using cells smaller than the typical size of an aggregated area. Cells in a given aggregated area are randomly color-coded for race and assigned population density in such a way that the total population and racial shares of the aggregated area 
are preserved. The racial landscape provides a visualization comparable to that of the one-dot-per-person map but is amenable to further analysis including quantification of segregation.

Table 1. summarizes existing resources for mapping racial distribution in US cities. Most of the resources are in the public domain, but the Social Explorer requires a fee for access to more specific data. Among the resources listed in Table 1, there is a lack of resources that can illustrate changes in the racial distribution over an extended period of time. The race question and race (or ethnicity) categories have been incorporated in every US Decennial Census since 1790, whereas data on the census tract level has been available since 1910. However, the long-term comparable studies on residential segregation are challenging due to changes in racial categorizations (Snipp 2003).

Our aim in this paper is to produce a dataset of temporal evolution of racial spatial configuration for major US cities. For each city, we construct a temporal series of racial maps going back as long as the data allows and ending in 2010. As the data for such dataset is in the public domain, our core contribution is to organize the data to constant features (by harmonizing boundaries of aggregation areas for all years) and to convert various historical categorizations of racial groups into a single categorization.

We use the neighborhood classification approach at the census tract level to map racial distribution; our map series shows the evolution of neighborhood types assigned to harmonized tracts. We use the term "neighborhood" loosely and identify it with a census tract. Maps are shapefiles with a number of attributes attached to each aggregated area (see section 2.4 for a list of attributes). Thus, the dataset has a dual purpose, it visually chronicles temporal changes in racial distribution and it doubles as an easy-to-use archive of historical racial data for long-term longitudinal studies. All means of racial analysis can be performed on this data including calculating composition, diversity, segregation, as well as constructing different types of maps showing more specific aspects of racial distribution.

The paper is organized as follows. Section 2 discusses the availability and sources of census tract data on racial composition. It also describes our method and its limitations. Section 3 consists of the case study for the use of our dataset - an application to Cook County, IL. Finally, discussion and conclusions follow in section 4. 
Table 1. Existing resources of spatial data and maps illustrating racial composition in the US cities

\begin{tabular}{|c|c|c|c|c|}
\hline Project & $\begin{array}{l}\text { Time } \\
\text { age }\end{array}$ & cover- & Region & Availability \\
\hline \multirow[t]{2}{*}{ Mixed Metro } & \multirow{2}{*}{$\begin{array}{l}1990 \\
2010\end{array}$} & \multirow[t]{2}{*}{2000} & \multirow{2}{*}{$\begin{array}{l}\text { State-by-state } \\
\text { or for } 53 \text { largest } \\
\text { metropolitan } \\
\text { areas. }\end{array}$} & http://mixedmetro. \\
\hline & & & & us/ \\
\hline \multirow{5}{*}{$\begin{array}{l}\text { Neighborhood } \\
\text { ethnic and racial } \\
\text { changes trajecto- } \\
\text { ries }\end{array}$} & \multirow{5}{*}{\multicolumn{2}{|c|}{$1970-2010$}} & \multirow{5}{*}{$\begin{array}{l}\text { New } \quad \text { York, } \\
\text { Chicago, } \quad \text { Los } \\
\text { Angeles, Houston }\end{array}$} & https://media. \\
\hline & & & & mikebader.net/ \\
\hline & & & & neighborhoodtrajectc \\
\hline & & & & projectdescription. \\
\hline & & & & html \\
\hline \multirow{2}{*}{$\begin{array}{l}\text { SocScape - di- } \\
\text { versity/dominant } \\
\text { race maps }\end{array}$} & \multirow{2}{*}{$\begin{array}{l}1990 \\
2010\end{array}$} & \multirow[t]{2}{*}{2000} & \multirow{2}{*}{$\begin{array}{l}\text { US, counties, } 363 \\
\text { MSAs }\end{array}$} & http://socscape. \\
\hline & & & & edu.pl \\
\hline \multirow{2}{*}{$\begin{array}{l}\text { SocScape - di- } \\
\text { versity/dominant } \\
\text { race change maps }\end{array}$} & \multirow{2}{*}{\multicolumn{2}{|c|}{$\begin{array}{l}1990-2000 \\
2000-2010 \\
1990-2000\end{array}$}} & \multirow{2}{*}{$\begin{array}{l}351 \text { Urban areas } \\
\text { within MSAs }\end{array}$} & http://socscape. \\
\hline & & & & edu.pl \\
\hline \multirow{4}{*}{$\begin{array}{l}\text { Racial dot map } \\
\text { from University of } \\
\text { Virginia }\end{array}$} & \multirow{4}{*}{\multicolumn{2}{|c|}{2010}} & \multirow[t]{4}{*}{ US } & https:// \\
\hline & & & & demographics. \\
\hline & & & & virginia.edu/ \\
\hline & & & & DotMap/ \\
\hline \multirow{6}{*}{$\begin{array}{l}\text { Racial dot map } \\
\text { from New York } \\
\text { Times }\end{array}$} & \multirow{6}{*}{\multicolumn{2}{|c|}{2010}} & \multirow[t]{6}{*}{ US } & https : //www . \\
\hline & & & & nytimes.com/ \\
\hline & & & & interactive/ \\
\hline & & & & 2015/07/08/us/ \\
\hline & & & & census-race-map. \\
\hline & & & & html \\
\hline \multirow{5}{*}{$\begin{array}{l}\text { Racial dot map } \\
\text { from The Wash- } \\
\text { ington Post }\end{array}$} & \multirow{5}{*}{\multicolumn{2}{|c|}{$\begin{array}{l}1990, \quad 2000, \\
2010,2016\end{array}$}} & \multirow[t]{5}{*}{ US } & https : //www . \\
\hline & & & & washingtonpost. \\
\hline & & & & com/graphics/ \\
\hline & & & & 2018/national/ \\
\hline & & & & segregation-us-citi \\
\hline \multirow{2}{*}{$\begin{array}{l}\text { SocScape - racial } \\
\text { dot maps }\end{array}$} & \multirow{2}{*}{\multicolumn{2}{|c|}{2010}} & \multirow[t]{2}{*}{ All counties } & http://socscape. \\
\hline & & & & edu.pl \\
\hline \multirow{3}{*}{$\begin{array}{l}\text { Urban Transition } \\
\text { Historical GIS } \\
\text { Project }\end{array}$} & \multirow{3}{*}{\multicolumn{2}{|c|}{$\begin{array}{l}1880 \\
1940\end{array}$}} & \multirow{3}{*}{$\begin{array}{l}39 \text { cities in } 1880, \\
69 \text { cities in } 1930 \\
\text { and } 1940\end{array}$} & https://s4.ad. \\
\hline & & & & brown.edu/Projects/ \\
\hline & & & & UTP2/index.htm \\
\hline \multirow[t]{2}{*}{ Social Explorer } & $1790-201$ & & US & https : //www \\
\hline & & & & socialexplorer.com/ \\
\hline
\end{tabular}




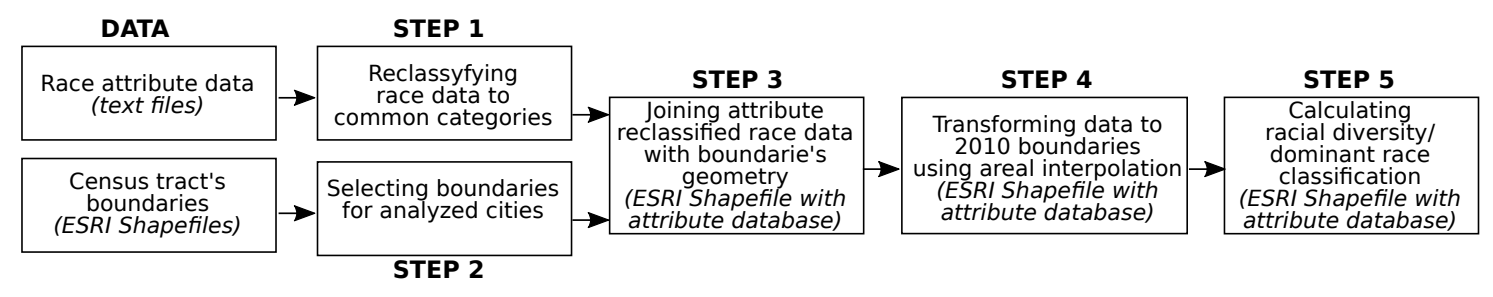

Figure 1. Preprocessing steps required to prepare multi-year comparable dataset for illustrating the spatiotemporal changes in racial geography in US major cities.

\section{Data and Method}

Creating maps that effectively illustrate changes in racial distribution over a long time is challenging because of the data format (attribute data and boundaries are available as separate files), changes in racial categorization, and changes in the census boundaries between decennials censuses.

Preparing the maps showing racial composition in the US cities over the 1910-2010 period requires several preprocessing steps (Figure 1). We preprocess data using $\mathrm{R}$ computational environment and its libraries designed to work with spatial data $(s l$, areal) and the base functions designed to work with tabular data stored in text files. In the following subsections, we describe the input data and the processing steps required to prepare our dataset - ESRI Shapefiles for 63 major US cities with harmonized census tracts and a single (time-invariant) categorization of racial groups.

\subsection{Race-specific data availability at census tract level}

\subsubsection{Census tract data availability}

The concept of census tract - an areal unit with relatively homogeneous population characteristics that would retain their boundaries from one census to another - was first introduced in 1906 for New York City by W. Laidlow (Krieger|2006, Laidlaw 1906 , Bureau of the Census 1994). Initially, census tracts were proposed as a framework for studying changes between decennial censuses (Laidlaw 1906) in planning congregation size and public health and services (i.e., for tracking morbidity and mortality rate). By the 1950 s, census tracts were used by government sectors and in research on health, immigration, crime, education, and residential segregation (Krieger|2006). Census tract 
has been adopted in the demographic studies as a proxy of the neighborhood, as they provide the best compromise regarding the size, homogeneity, data availability, and comparability (White 1988). Census tracts are widely used to study trends in the racial composition of the US.

Race-specific data at census tract level for 1910-2010 were downloaded from the NHGIS project. In 1910 census tract data was delineated for eight US cities with a population exceeding 500,000 (New York City, Baltimore, Boston, Chicago, Cleveland, Philadelphia, Pittsburgh, St.Louis). Census tract data was again collected for the same eight cities in 1920. However, for 1910, only data for New York City is currently available, and for 1920, data is currently available only for Chicago, Cleveland, and New York City. In 1930, ten more cities introduced division into census tracts, increasing the number of cities to 18. In 1940 all but one city over 250,000 and 25 cities with a population exceeding 100,000 were divided into census tracts. Since the 1940 US Decennial Census, the number of major cities covered by census tracts has regularly increased. In the 2000 US Decennial Census, census tracts were for the first time delineated nationwide (Green 1937, Bureau of the Census 1994).

The number of cities divided into census tracts increased from census to census. The longest series of census data is available for New York City (since 1910) and Chicago and Cleveland (since 1920). We selected 63 cities for which data is available since at least 1950 (Figure 2). Among selected cities,1 city has tract data available from 1910, 2 cities have tract data available from 1920, 13 cities have tract data available since 1930, 33 cities have data available since 1940, and 14 cities have data available since 1950. A detailed list of cities for which data in a particular year is available is included in Table S1 in the supplementary material. The term "city" is used here to describe a collection of census tracts within the 2010 boundary of a corresponding Metropolitan Statistical Area (MSA) for which data is available.

\subsubsection{Race attribute data sources}

We downloaded data at census tract level for 1910-2010 from the National Historical Geographic Information System (NHGIS) project (Manson et al. 2019). Race-specific attribute data is stored as 23 separate text files. 


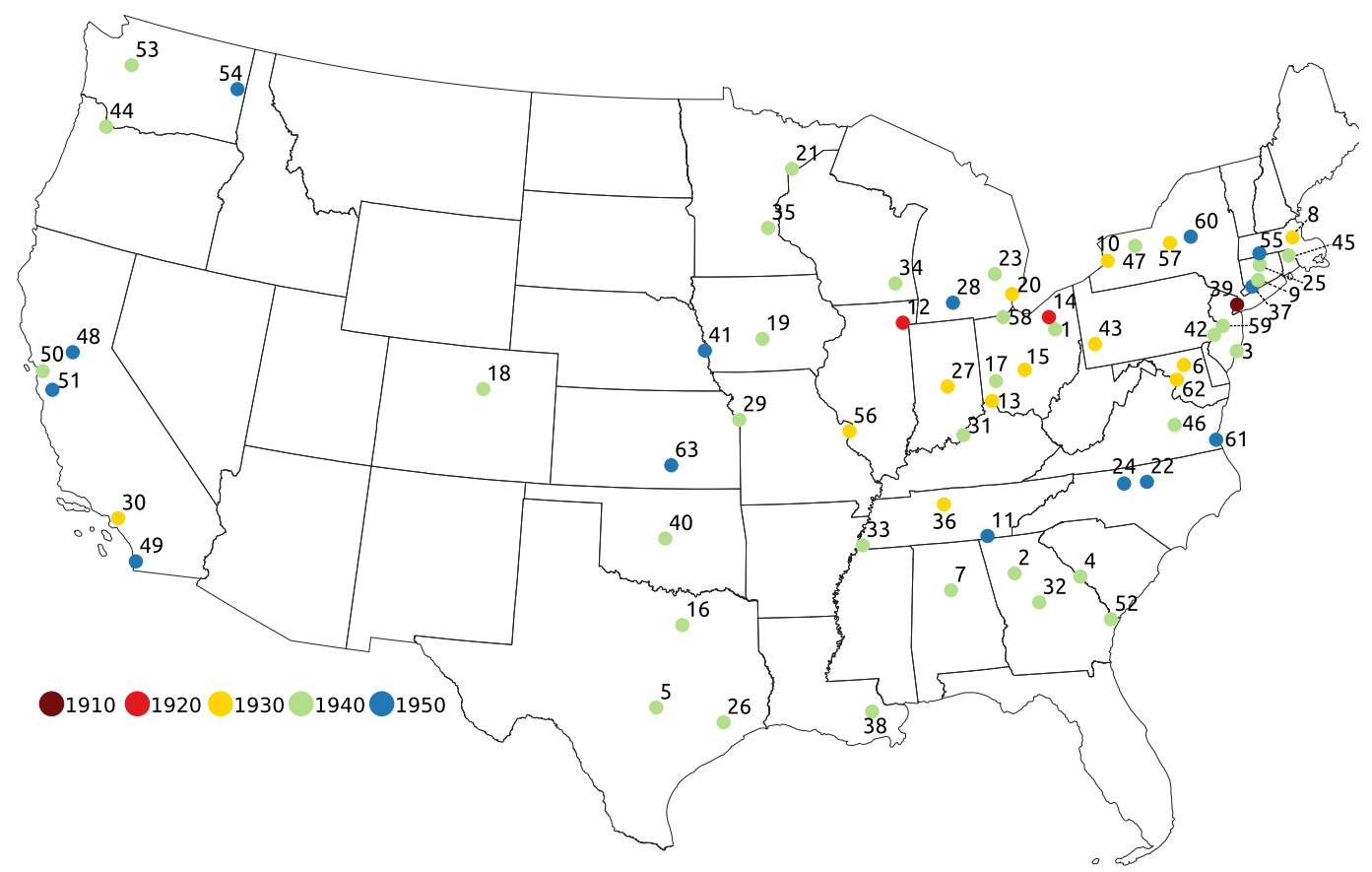

Figure 2. List of US cities included in the database: 1-Akron,OH; 2-Atlanta,GA; 3-Atlantic City, NJ; 4Augusta, GA; 5-Austin, TX; 6-Baltimore, MD; 7-Birmingham, AL; 8-Boston, MA; 9-Bridgeport, CT; 10Buffalo, NY; 11-Chattanooga, TN; 12-Chicago, IL; 13-Cincinnati, OH; 14-Cleveland, OH; 15-Columbus, OH; 16-Dallas, TX; 17-Dayton, OH; 18-Denver, CO; 19-Des Moines, IA; 20-Detroit, MI; 21-Duluth, MN; 22-Durham, NC; 23-Flint, MI; 24-Greensboro, NC; 25-Hartford, CT; 26-Houston, TX; 27-Indianapolis, IN; 28-Kalamazoo, MI; 29-Kansas City, MO; 30-Los Angeles, CA; 31-Louisville, KY; 32-Macon, GA; 33-Memphis, TN; 34Milwaukee, WI; 35-Minneapolis, MN; 36-Nashville, TN; 37-New Haven, CT; 38-New Orleans, LA; 39-New York, NY; 40-Oklahoma City, OK; 41-Omaha, NE; 42-Philadelphia, PA; 43-Pittsburgh, PA; 44-Portland,OR; 45Providence, RI; 46-Richmond, VA; 47-Rochester, NY; 48-Sacramento, CA; 49-San Diego, CA; 50-San Francisco, CA; 51-San Jose, CA; 52-Savannah, GA; 53-Seattle, WA; 54-Spokane, WA; 55-Springfield, MA; 56-St. Louis, MO; 57-Syracuse, NY; 58-Toledo, OH; 59-Trenton, NJ; 60-Utica, NY; 61-Virginia Beach, VA; 62-Washington, DC; 63-Wichita, KS. Color indicates the starting year of time series.

We used the following attribute datasets: (1) 1910 Census: Population Data for New York; (2) 1920 Census: Population \& Housing Data for New York NY, Cleveland OH, Chicago IL (3 separate files); (3) 1930 Census Population \& Housing Data for Chicago IL, Cincinnati OH, Cleveland OH, Detroit MI, Nashville TN, New York NY, St.Louis MO, Syracuse NY, Washington DC and two files containing data for selected areas located in the following states: IN, MA, NT, OH, PA and CA, MD, MA, MO, NY, TN (11 separate files); (4) 1940 Census: Population \& Housing Data [Tracts \& NY Health Areas: Major Cities \& Surrounds]; (5) 1950 Census: Population \& Housing Data [Tracts: Major Cities \& Surrounds]; (6) 1960 Census: Population \& Housing Data [Tracts: Major Cities \& Surrounds]; (7) Nominally integrated time series tables 1970-2010: 1970 Census: Count 2 - 100\% Data [Tracts, Urban Areas, Metro Areas, etc.]; (8) Nominally integrated time series tables 1980-2010: Persons by Hispanic or 
Table 2. Race categorization $1910-2010$

\begin{tabular}{|c|c|c|c|}
\hline Year & Race categories & $\begin{array}{l}\text { Reclassified race cat- } \\
\text { egories }\end{array}$ & $\begin{array}{l}\text { Neighborhood } \\
\text { types }\end{array}$ \\
\hline $\begin{array}{l}1910 \\
1920 \\
1930\end{array}$ & $\begin{array}{l}\text { White divided by par- } \\
\text { ents nativity (native, } \\
\text { mixed, foreign born); } \\
\text { Blacks; Other race (in- } \\
\text { clude Asians and Amer- } \\
\text { ican Indians) }\end{array}$ & $\begin{array}{l}\text { White; Black; Asian } \\
\text { and American Indian }\end{array}$ & $\begin{array}{l}\text { WL, WM, BL, BM, } \\
\mathrm{AL}, \mathrm{AM}, \mathrm{HD}\end{array}$ \\
\hline 1940 & White; Nonwhite & White; Black & WL, WM, BL, BM \\
\hline $\begin{array}{l}1950 \\
1960\end{array}$ & $\begin{array}{l}\text { White; Black; Other } \\
\text { race (include Asians } \\
\text { and American Indians) }\end{array}$ & $\begin{array}{l}\text { White; Black; Asian } \\
\text { and American Indian }\end{array}$ & $\begin{array}{l}\text { WL, WM, BL, BM, } \\
\mathrm{AL}, \mathrm{AM}, \mathrm{HD}\end{array}$ \\
\hline 1970 & $\begin{array}{l}\text { White; Black or African } \\
\text { American; American In- } \\
\text { dian and Alaska Native; } \\
\text { Asian and Pacific Is- } \\
\text { lander and Other Race }\end{array}$ & $\begin{array}{l}\text { White; Black; Asian } \\
\text { and American Indian }\end{array}$ & $\begin{array}{l}\text { WL, WM, BL, BM, } \\
\mathrm{AL}, \mathrm{AM}, \mathrm{HD}\end{array}$ \\
\hline $\begin{array}{l}1980- \\
2010\end{array}$ & $\begin{array}{l}\text { NH White; NH Black; } \\
\text { NH American Indian; } \\
\text { Alaska Native; Asian } \\
\text { or Pacific Islander; NH } \\
\text { Some other race; NH } \\
\text { Two or more races; His- } \\
\text { panic or Latino divided } \\
\text { into } 5 \text { racial categories }\end{array}$ & $\begin{array}{l}\text { NH White, NH Black, } \\
\text { NH Asian and Ameri- } \\
\text { can Indian, NH Other } \\
\text { race, Hispanic }\end{array}$ & $\begin{array}{l}\text { WL, WM, BL, BM, } \\
\text { AL, AM, OL, OM, } \\
\text { HL, HM, HD }\end{array}$ \\
\hline
\end{tabular}

Latino Origin by Race.

\subsubsection{Census tract boundaries and their harmonization}

The census tracts boundaries were also downloaded from the NHGIS project. Census tract boundaries are available as ESRI Shapefiles as one file per year containing all cities for which census tract for a particular year were delineated. Among the location attributes (code of states and counties), the NHGIS project provides the GISJOIN field to join attribute data to GIS boundaries. We downloaded census tract boundary files for the years 1910-2010.

Boundaries of census tracts are not kept constant over time. In every decennial 
census, many tracts are split, consolidated, or changed in other ways from the previous boundaries to reflect population growth or decline (Logan 2014). Because the constant boundaries are essential for long-term, multi-year comparable studies, methods were introduced to transform data from one set boundary to another. These methods can be divided into two main groups: areal weighting interpolation and dasymetric modeling. In areal weighting interpolation, the values (i.e., population) are assigned to the target unit in proportion to the percentage of the area where the source unit covers the target unit (Goodchild and Lam 1980, Goodchild et al. 1993, Langford and Unwin 1994). The source units are the original set of boundaries in which data is aggregated and the target units are the resulting set of boundaries into which we distribute a given data. Dasymetric modeling uses ancillary data of spatial resolution higher than census tracts to disaggregate input tracts into finer units Wright 1936, Eicher and Brewer 2001, Mennis 2003, Petrov 2012 and to aggregate the finer units to the boundaries of target tracts. Dasymetric modeling requires the use of ancillary data (for example, the land cover data) comparable between the years (Dmowska 2019). Because there is no comparable ancillary dataset that can be used for the period of 1910-2010, we harmonize tract boundaries in all years to their 2010 boundaries using areal weighting interpolation implemented in the $\mathrm{R}$ package areal (Prener and Revord 2019). This package ensures that all inhabitants within input boundaries are allocated to target boundaries, even in the situation when, due to the data quality issue, the boundaries are non-overlapping.

\subsection{Time-invariant categorization of racial groups}

The race question and race (or ethnicity) categories have been incorporated in every US Decennial Census since 1790. Data on Hispanic origin has been collected since 1980 (Humes and Hogan 2009). Until the 1950 US Census, an individual's race was determined by census-takers (enumerators). Since the 1960 US Census, self-enumeration was introduced, and the Americans could declare their own race.

The available racial categories have changed between censuses, as the meaning of race has changed over the years. Changes in racial categorization show that racial classification reflects demographic, political, and ideological shifts in US society (Lee 
1993). Changes in the racial make-up of the US population and changes in social attitudes have contributed to how people are categorized in the United States Bennett 2000). Bennett (2000) points out that racial categories used in 1910-2010 censuses depict the transition from the predominantly bi-racial society (White/Black) to one composed of many different racial/ethnicity groups.

The US Census Bureau provides useful interactive visualization (https://www. census.gov/data-tools/demo/race/MREAD_1790_2010.html) showing how race and ethnicity categories have changed over time since the first census in 1790. A similar tool is provided by Pew Research Center (https://www.pewresearch.org/ interactives/what-census-calls-us/). The aforementioned visualizations allow us to understand better the relationship between historical classifications and the present classification. The detailed description of the aforementioned changes in the racial categorization has been widely discussed in many publications; for detailed information, see for example Bennett (2000), Gauthier (2002), Humes and Hogan (2009), Lee (1993), Nobles (2000), Snipp (2003).

The racial categories reported at the census tract level during the 1910-2010 period are summarized in Table 2. This table lists the original racial categorizations, our single (time-invariant) racial categorization, and our neighborhood types for each year between 1910 and 2010. We aimed at providing a single racial categorization for the period 1910-2010 that is as consistent with the original classifications as possible. The assignment of our categories to the original categories is shown in Figure 3. Our categorization has five race categories, White, Black, Asian, Hispanic, and Others. However, for the 1910-1970 period only the first three categories are used due to the fact that until 1970 the Hispanic population was included in the White category. Thus, even if the exact one-to-one assignment of historical racial categorizations to a timeinvariant racial categorization is not possible, our time-invariant categorization shown in Figure 3 offers a reasonable approximation. As Snipp (2003) pointed out "it should be possible for researchers to pursue temporal comparison [of racial categories] if they maintain a healthy degree of skepticism about the precision of the results." 


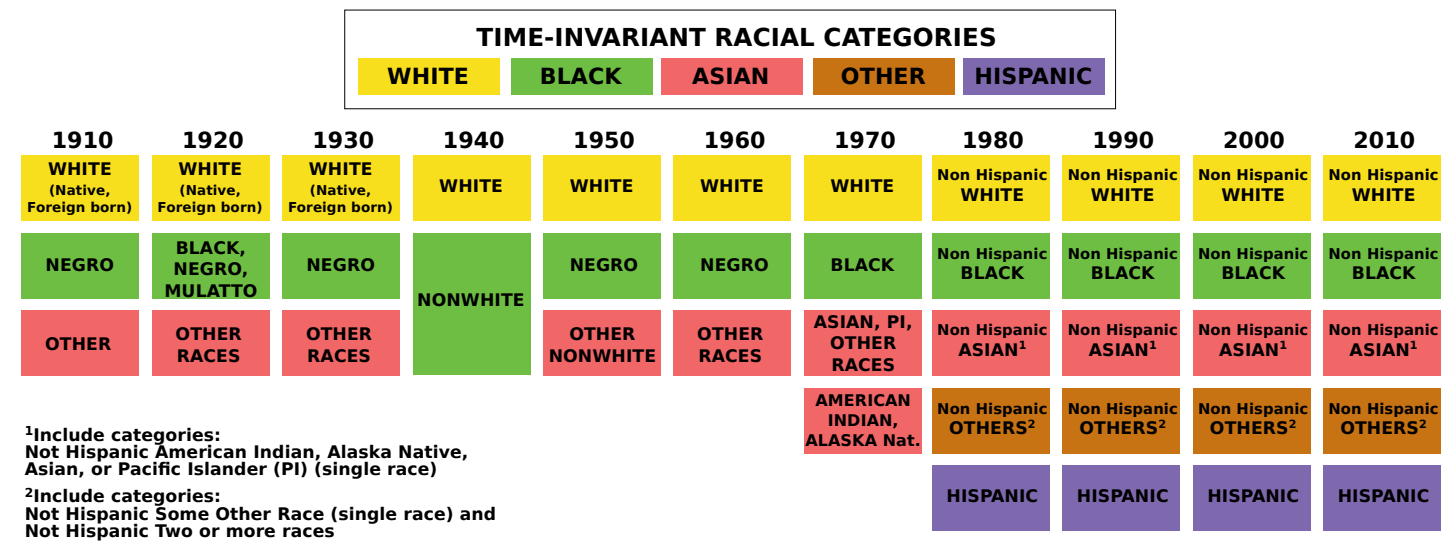

Figure 3. Race categorization 1910-2010

\subsection{Classification of tracts into neighborhood types}

Observing time evolution (dynamics) of racial distribution in a given city is achieved by noticing changes in a pattern of values (colors) assigned to an attribute used to make a legend. The race itself is not an attribute of a tract for racial mapping because most tracts are not mono-racial. We use a neighborhood type attribute to make a default legend. We classified tracts into neighborhood types on the basis of tract's racial diversity and its dominant race Holloway et al. (2012). We refer to these types as diversity/dominant race types (DDR types). Comparing a map of DDR types with a one-dot-per-person map which uses the race attribute directly reveals that a map of DDR types is an excellent approximation of the racial distribution map (compare the map of DDR types for 2010 in Figure 6 with the dot map in Figure 1 in the paper by (Dmowska et al. 2020)).

We define DDR types using a scheme similar to Holloway et al. (2012). First, census tracts are classified into three categories of diversity (low, medium, and high) on the basis of the value of the standardized entropy $(E)$ of their racial composition and shares of dominant/subdominant racial category. Second, low and medium diversity census tracts are further divided based on the identity of the dominant race. Standardized entropy $(E)$ is calculated using a formula:

$$
E=-\frac{1}{E_{\max }} \sum_{k=1}^{K} p_{k} \ln \left(p_{k}\right),
$$




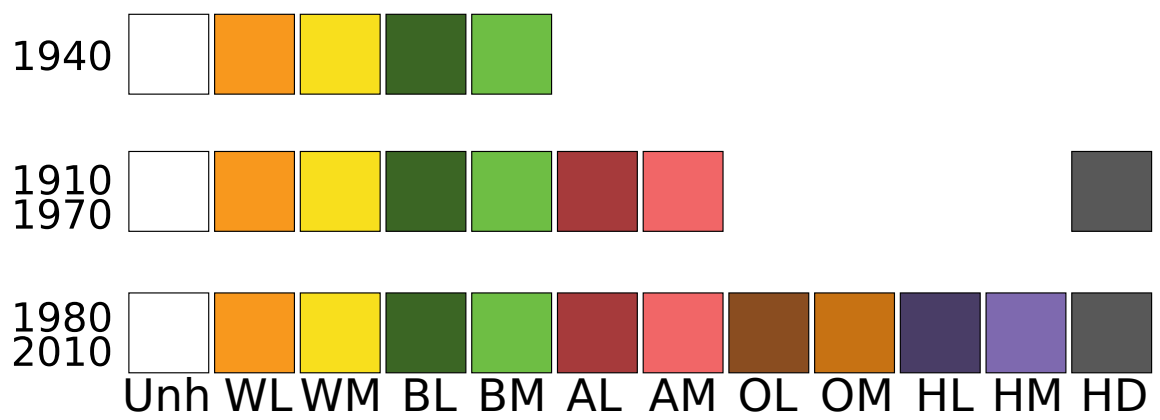

Figure 4. Legend of racial diversity/dominant race (DDR) classification. Explanation: Unh - uninhabited areas; WL - low diverse, dominated by Whites; WM - medium diverse, dominated by Whites; BL - low diverse, dominated by Blacks; BM - medium diverse, dominated by Blacks; AL - low diverse, dominated by Asians or American Indians; AM - medium diverse, dominated by Asians or American Indians; OL - low diverse, dominated by others; OM - medium diverse, dominated by others; HL - low diverse, dominated by Hispanics/Latino; HM - medium diverse, dominated by Hispanics/Latino; HD - high diverse

where $K$ is the number of racial groups, $k=1, \ldots, K$ is an index of racial groups, $p_{k}$ is a fraction of $k$ subpopulation relative to the entire tract's population. $E_{\max }=-\ln (1 / K)$ is the maximum value of entropy (when all $K$ subpopulations contribute equally to the entire tract's population). The value of entropy is dependent on the number of groups $(K)$ present. The standardized entropy has the range between 0 (the tract is inhabited by only one racial group) to 1 (all racial groups are equally represented in the census tract). The natural logarithm is used in Eq.(1).

Low diversity category (L) is assigned to census tracts with the share of dominant race higher than $80 \%$ and $E<E_{L} . E_{L}$ is an entropy threshold that corresponds to the situation when the dominant subpopulation constitutes $81 \%$ of the entire tract's population, and the remaining subpopulations contribute equally. High diversity category (HD) is assigned to the census tract fulfilling three conditions: (1) no single race consists of more than $50 \%$ of tract's population, (2) the sum of shares of two most dominated races does not exceed $80 \%$ of tract's population, and (3) $E>E_{H}$. $E_{H}$ corresponds to the situation when the dominant subpopulation constitutes $50 \%$, subdominant population constitutes $30 \%$ of the entire tract's population, and the remaining subpopulations contribute equally. Note that with only two race groups, a high diversity class cannot be calculated. All remaining census tracts are classified as medium diversity $(\mathrm{M})$.

Applying DDR classification to harmonized tracts and using shares of time-invariant racial categories, we obtain 5, 8, or 12 DDR types (including an uninhabited type) 

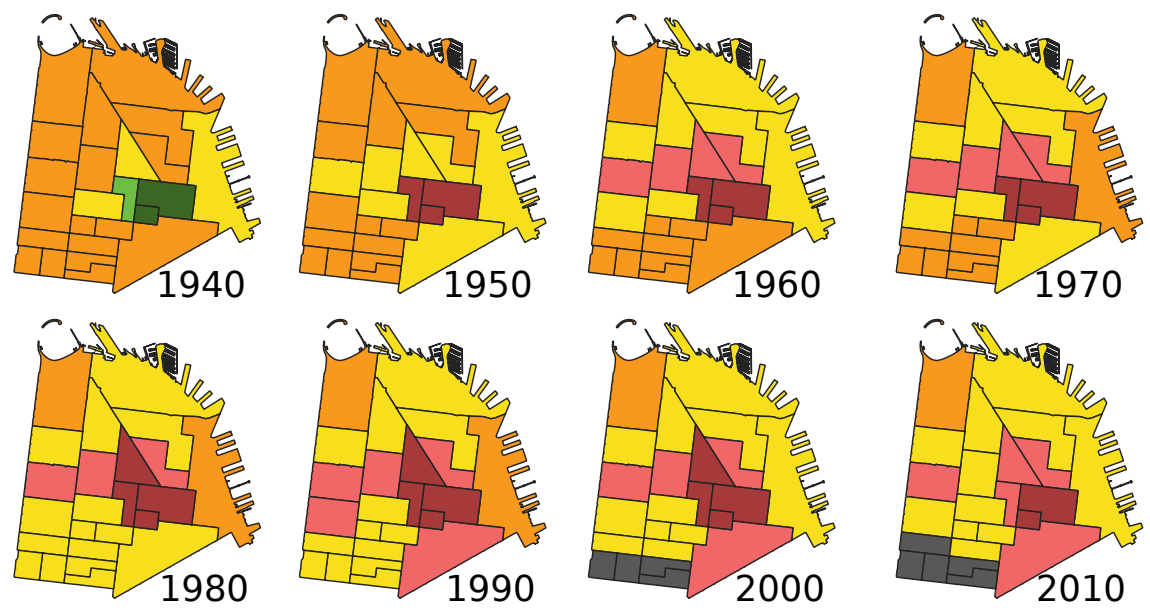

WL WM BL BM AL AM HD

Figure 5. The changes in the racial composition in the Chinatown neighborhood in San Francisco.

depending on the census year. Figure 4 shows the legend for racial diversity maps at different census years.

\subsubsection{Limitations of time-invariant racial categorization}

Limitations of the data result in occasional problems with our time-invariant racial categorization, and, in turn with our neighborhood types classification. One problem may arise when visualizing the Asian subpopulation. Figure 5 shows an example of such a case - a Chinatown neighborhood located in the northeast part of San Francisco, CA. A noticeable feature of the series of maps shown in Figure 5. is that the "Chinatown" in 1940 is indicated as a Black enclave, but reverts to a correct Asian-dominated type in 1950. This is an artifact stemming from the fact that 1940 data distinguishes only between White and non-White populations. As the Black population in 1940 consisted of $9.8 \%$ of the US population, whereas the Asian population consisted only of $0.2 \%$ we decided to assign a Black time-invariant category to the non-White 1940 category. In rare cases, of which an area shown in Figure 5 is an example, such an assumption is incorrect. In Figure 5 the tracts showing Black dominance in 1940 where really Asian-dominated. More generally, neighborhoods in 1940 that were Asian-dominated will be shown as Black-dominated; there were very few such neighborhoods.

Another problem is the "sudden" appearance of Hispanic-dominated neighborhoods 
Table 3. Changes in racial metrics in Cook County during the 1920-2010 period

\begin{tabular}{lllllllll}
\hline Year & Whites & Blacks & Asian & Hispanics & Others & $E$ & $N_{\mathrm{H}}$ & $H$ \\
\hline 1920 & 95.82 & 4.07 & 0.11 & & & 0.16 & 1.29 & $0.54(0.59)$ \\
1930 & 92.34 & 6.93 & 0.73 & & & 0.27 & 1.54 & $0.72(0.76)$ \\
1940 & 91.69 & 8.31 & & & & 0.41 & 1.93 & $0.81(0.84)$ \\
1950 & 87.98 & 11.62 & 0.4 & & & 0.35 & 1.75 & $0.72(0.76)$ \\
1960 & 82.67 & 16.79 & 0.54 & & & 0.44 & 2.03 & $0.76(0.78)$ \\
1970 & 77.21 & 21.55 & 1.24 & & & 0.53 & 2.34 & $0.74(0.75)$ \\
1980 & 62.60 & 25.41 & 2.32 & 9.51 & 0.16 & 0.60 & 2.62 & $0.58(0.59)$ \\
1990 & 57.11 & 25.49 & 3.70 & 13.6 & 0.10 & 0.66 & 2.89 & $0.52(0.53)$ \\
2000 & 48.33 & 26.26 & 5.03 & 20.24 & 0.14 & 0.74 & 3.29 & $0.48(0.48)$ \\
2010 & 44.47 & 24.71 & 6.37 & 24.30 & 0.15 & 0.77 & 3.45 & $0.43(0.43)$ \\
\hline
\end{tabular}

Composition in \%. Entries in brackets are calculated using non-harmonized

tracts' data.

in 1980. Such appearance can be seen in Figure 6 where the map series indicates the absence of Hispanics in Chicago until 1980 at which year they appear to form few relatively significant enclaves. In reality, Hispanics were already present there in 1970 or earlier but before 1980 they there were counted as Whites in the absence of the Hispanic category.

\subsection{Dataset availability}

A dataset of time-series of racial distribution maps for 63 US cities is available for download from http://socscape.edu.pl. Data can be downloaded by the name of the Metropolitan Statistical Area either as ESRI shapefiles (with the QGIS legend to map DDR types) or pdf files. Each ESRI shapefile consists of the set of the census tract described by the following attributes: (1) location information (FIPS code and name of county, state, MSA, and tract information) and GISJOIN field based on the 2010 US Decennial Census, (2) a total number of population, (3) the number of subpopulations by given race, (4) percent of a given race, (5) DDR class. The race-specific information is given for each available year, and it is based on the time-invariant racial categories. The default spatial display is the map of DDR types. Such map shows the spatioracial character as a single, easy-to-understand map and can be used to illustrates the evolution of racial geography in US metropolitan areas. 


\section{Mapping evolution of racial distribution in Cook County, IL}

To chronicle the evolution of racial distribution in Cook County we have downloaded from http://socscape.edu.pl the data for Chicago MSA and trimmed it to the 2010 boundaries of Cook County. Cook County, a core part of Chicago, is the secondmost-populous county in the United States. Due to its location, Chicago in the 19th century became a rapidly growing city, with a population of 10,000 in 1840 and 1 million in 1890. Chicago's racial composition has been hugely shaped by three waves of migration discussed in the Introduction section. Temporal changes in Cook County racial composition, as well as changes to metrics of racial diversity ( $E$ and $N_{\mathrm{H}}$ ) and segregation (Theil index $H$ ) are shown in Table 3. Values in this table are calculated using harmonized tracts except for the values in brackets that are calculated using original tracts. Racial diversity is commonly measured by the value of entropy $E$ but, in our opinion, $E$ is not interpretable, therefore we prefer to use the Hill number $N_{\mathrm{H}}=e^{E E_{\max }}$ Hill $(1973) \cdot N_{\mathrm{H}}$ is interpreted as the effective number of racial categories present in a city or the number of different racial groups that contribute significantly to the city's composition. $N_{\mathrm{H}}$ is not an integer number, so should be rounded up or down to get the number of racial groups and thus the true population's diversity. From Table 3 we observe Cook County steadily increased its diversity and decreased its segregation during the 1920-2010 period, however, according to the recent segregation study (Dmowska and Stepinski 2021), Cook County has been the most segregated county in the US in 2010 .

The primary aim of this work is not to collect racial metrics for the 1920-2010 period, but rather to chronicle the changes in the spatial configuration (topology) of racial distribution during this period. Figure 6 shows such configurational changes in Cook County in ten point-in-time snapshots. This sequence of maps illustrates a dramatic change of Cook County's racial character (composition and configuration) over the 90 years. The change was occurring at a slow pace during the 1920-1960 period but the pace of change has exploded after 1960. Temporal changes in racial segregation can visually be assessed from the map series in Figure 6. Recall that darker colors (WL, $\mathrm{BL}, \mathrm{AL}$, and $\mathrm{HL}$ ) correspond to (almost) mono-racial regions while lighter colors (WM, 


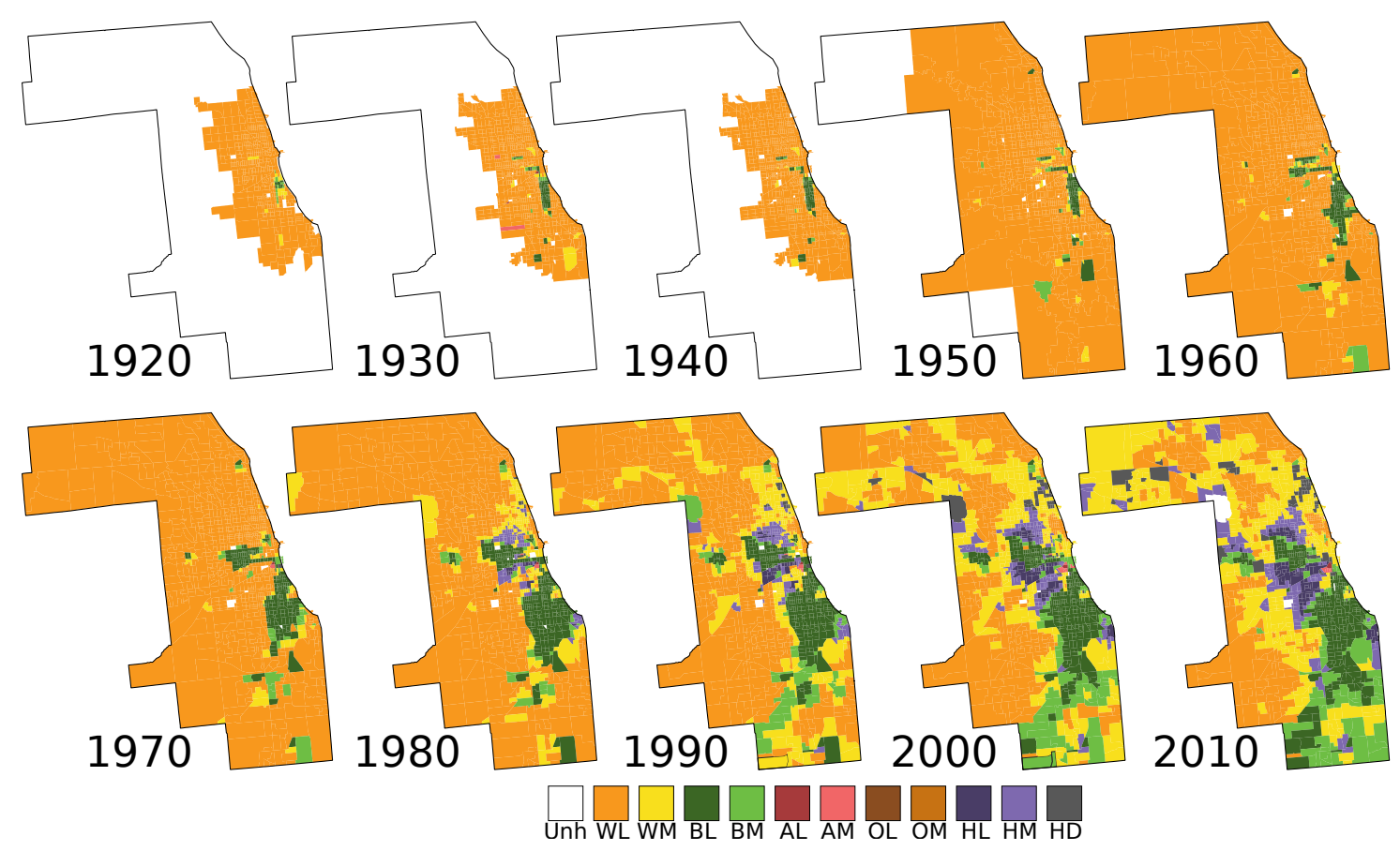

Figure 6. Evolution of the spatial distribution of the DDR types in Cook County, IL (1920-2010). Track boundaries are not shown to avoid obscuring the pattern Legend: Unh - uninhabited areas; WL - low diverse, dominated by Whites; WM - medium diverse, dominated by Whites; BL - low diverse, dominated by Blacks; BM - medium diverse, dominated by Blacks; AL - low diverse, dominated by Asians or American Indians; AM - medium diverse, dominated by Asians or American Indians; OL - low diverse, dominated by others; OM medium diverse, dominated by others; HL - low diverse, dominated by Hispanics/Latino; HM - medium diverse, dominated by Hispanics/Latino; HD - high diverse.

BM, AM, and HM) correspond to more racially diverse regions. The darker the colors on the map the more racially segregated is the city. Such visual assessment of Figure 6 points to high levels of racial segregation in Cook County during the 1920-1970 period followed by a decreasing level of segregation in the subsequent decades. This is in agreement with the temporal changes in the value of $H$ shown in Table 3.

From the configurational (topological) perspective, Cook County starts in 1920 as the White region with a small Black enclave. The increase in the share of the region inhabited predominantly by Blacks proceeds through the growth of this first enclave and by the creation of new, initially very small, enclaves which, however, start to grow once established. After a while, separate enclaves may merge into a single much larger enclave. A similar topology change is observed in the evolution of Hispanic enclaves. This specific way of the development of racial pattern evolved in Cook County was first noticed by Stepinski and Dmowska (2020). They noticed that such behavior has all hallmarks of a type of dynamical process called preferential attachment (Perc 
2014). Sequences of point-in-time snapshots for 13 other cities can be viewed on the http://socscape.edu.pl website directly, without a need to download the data. For most Midwest cities the character of racial evolution is similar to what Figure 6 shows for Cook County - a slow change until 1960 and an accelerated change afterward having traits of preferential attachment dynamics.

Further investigation of the hypothesis that changes of racial distribution in (at least some) US cities occur via preferential attachment process is beyond the scope of this paper. Here, we bring up this issue to underscore the potential of long-term series of racial distribution maps for suggesting a mechanism of the change, and, eventually, to serve as a check on models of segregation.

\section{Discussion}

In this paper, we reported on the development of a dataset of 1910-2010 series of racial distribution maps for 63 major US cities that have racial data at the census tract level dating back from as long ago as 1910 but no later than 1950. The dataset is expandable by the addition of data from future censuses starting with the US Census 2020 .

The key feature of the dataset is the time-invariant categorization of racial groups that allows for all maps in the series to have the same legend. Our primary purpose for this work was not to collect data from the 1910-2010 period so our dataset can serve as a depository of historical and present racial data for an à la carte use. For such use, the data with original tract boundaries and the original racial categorization would be preferable. Instead, our dataset is meant to enable long-term longitudinal studies of the racial character of the population in US cities. Moreover, the advantage of this dataset is the ability to produce series of maps like the one for Cook County shown in Figure 6. This is similar to the functionalities of resources like Mixed Metro or SocScape (see Table 1), which however extend over much shorter periods of time. The ability to summarize and visualize racial geography in the form of a temporal series of maps, all with the same legend, provides information about changes in geometric configuration of racial distribution, which, in turn, provides insight into the mechanism behind the evolution of racial segregation. In the rest of this section, we discuss aspects 
of our methodology that may raise questions.

We don't map racial categories directly because we want to have a single map for each year. A common way to map the distribution of racial categories is to map the spatial distribution of each category on a separate map leading to multiple maps for each year. A single-map option is a one-dot-per-person map, but such maps tend to be quite busy and more difficult to interpret than maps of neighborhood types. As we mentioned in section 2.3, neighborhood types maps show the same geometric configuration as dot maps.

We decided to use a particular classification of neighborhoods first introduced by Holloway et al. (2012) especially for cities in the US. One frequently asked question is whether a map of neighborhood types based on this classification depends on values of thresholds used to separate low/medium and medium/high diversity categories? Holloway et al. (2012) carefully examined values of thresholds and chose ones that fit the US context and its associated civil rights legislation (Ellis et al. 2018). Small changes in the values of thresholds would introduce slightly different maps whereas large changes in thresholds would not be justified. Our method requires the harmonization of census tracts to 2010 boundaries. Any transformation of boundaries introduces some change in the values of segregation metrics. Our harmonization procedure introduces a very small change in the value of Theil index $H$ (see the last column in Table 3). Composition and values of diversity metrics are not changed by the transformation of tracts' boundaries because they are based on population data for the entire region that does not depend on how the region is partitioned into tracts.

In our categorization, we don't distinguish between race and ethnicity. This is because in order to obtain a time-independent categorization we use a small number of categories. For our purpose a distinction between race and ethnicity is a secondary issue, we use the term "race" as a shortcut for a specific subgroup of the population. Time-invariant race categorization introduces errors; some of these errors were highlighted in section 2.3.1. Our goal is not to obtain a perfect time-invariant classification, but rather, a good enough classification that serves our purpose - it enables long-term longitudinal analysis and mapping. For example, our observations regarding changes in geometric configuration seen on the series of maps of Cook County (Figures 
6) would not change by considering original categorizations, but it would make the process much more difficult.

Finally, throughout this paper, we advocate for visual analysis of map series. This is not because we underestimate the value of quantitative analysis (through racial metrics), but rather because the visual analysis can yield information that is not obtainable by using current quantitative tools. In particular, we focus on temporal changes in the configuration of the pattern formed by different neighborhood types. Such changes are directly related to the type of process that drives racial dynamics. Racial metrics are not sufficient to inform about the character of such a process. Future research will attempt to simulate the process of preferential attachment (currently our best candidate for the driver of racial change) and checking the results versus the time series of maps from the dataset described in this paper.

\section{References}

Bader, M.D. and Warkentien, S., 2016. The fragmented evolution of racial integration since the civil rights movements. Sociological Science, 3, 133-166.

Bellman, B., et al., 2018. Local Population Change and Variations in Racial Integration in the United States, 2000-2010. International Regional Science Review, 41(2), 233-255.

Bennett, C., 2000. Racial categories used in the decennial censuses, 1790 to the present. Government Information Quarterly, 17(2), 161-180.

Bureau of the Census, 1994. Geographic areas reference manual. Bureau of the Census.

Burgess, E.W., 2015. The growth of the city: an introduction to a research project. Routledge.

Clark, W.A., et al., 2015. A multiscalar analysis of neighborhood composition in Los Angeles, 2000-2010: A location-based approach to segregation and diversity. Annals of the Association of American Geographers, 105(6), 1260-1284.

Dmowska, A., Stepinski, T.F., and Nowosad, J., 2019. Racial Landscapes - a patter-based, zoneless method for analysis and visualization of racial topography. Computers, Environment and Urban Systems, submitted.

Dmowska, A., 2019. Dasymetric modelling of population distribution-large data approach. Quaestiones Geographicae, 38(1), 15-27.

Dmowska, A. and Stepinski, T.F., 2019. Racial dot maps based on dasymetrically modeled gridded population data. Social Sciences, 8(5), 157. 
Dmowska, A. and Stepinski, T.F., 2021. Improving assessment of urban racial segregation by partitioning a region into racial enclaves. Environment and Planning B: Urban Analytics and City Science, 23998083211001386.

Dmowska, A., Stepinski, T.F., and Nowosad, J., 2020. Racial Landscapes-a pattern-based, zoneless method for analysis and visualization of racial topography. Applied Geography, $122,102239$.

Du Bois, W.E.B., 1899. The Philadelphia Negro: A social study. University of Pennsylvania Press.

Eicher, C.L. and Brewer, C.A., 2001. Dasymetric mapping and areal interpolation: Implementation and evaluation. Cartography and Geographic Information Science, 28(2), 125-138.

Ellis, M., et al., 2018. Remaking white residential segregation: metropolitan diversity and neighborhood change in the United States. Urban Geography, 39(4), 519-545.

Farrell, C.R., 2008. Bifurcation, fragmentation or integration? The racial and geographical structure of US metropolitan segregation, 1990-2000. Urban Studies, 45, 467-499.

Fasenfest, D., Booza, J., and Metzger, K., 2004. Living Together : A New Look at Racial and Ethnic Integration in Metropolitan Neighborhoods, 1990-2000. Brookings Institution.

Fischer, C.S., et al., 2004. Distinguishing the geographic levels and social dimensions of US metropolitan segregation, 1960-2000. Demography, 41(1), 37-59.

Fischer, M.J., 2003. The relative importance of income and race in determining residential outcomes in US urban areas, 1970-2000. Urban Affairs Review, 38(5), 669-696.

Fowler, C.S., Lee, B.A., and Matthews, S.A., 2016. The contributions of places to metropolitan ethnoracial diversity and segregation: Decomposing change across space and time. Demography, 53(6), 1955-1977.

Gauthier, J.G., 2002. Measuring America: the decennial censuses from 1790 to 2000. US Department of Commerce, US Census Bureau.

Goodchild, M.F., Anselin, L., and Deichmann, U., 1993. A framework for the areal interpolation of socioeconomic data. Environment and planning A, 25(3), 383-397.

Goodchild, M.F. and Lam, N.S.N., 1980. Areal interpolation: a variant of the traditional spatial problem. Department of Geography, University of Western Ontario London, ON, Canada.

Green, H.W., 1937. Census tracts in American cities. Department of Commerce, Bureau of the Census.

Gregory, I.N. and Healey, R.G., 2007. Historical GIS: structuring, mapping and analysing geographies of the past. Progress in human geography, 31(5), 638-653. 
Groves, P.A. and Muller, E.K., 1975. The evolution of black residential areas in late nineteenthcentury cities. Journal of Historical Geography, 1 (2), 169-191.

Hill, M.O., 1973. Diversity and evenness: a unifying notation and its consequences. Ecology 54, 427-432., 54, 427-432.

Holloway, S.R., Wright, R., and Ellis, M., 2012. The racially fragmented city? Neighborhood racial segregation and diversity jointly considered. The Professional Geographer, 64, 63-82.

Hong, S.Y., O’Sullivan, D., and Sadahiro, Y., 2014. Implementing spatial segregation measures in R. PlosS one, 9(1), e113767.

Humes, K. and Hogan, H., 2009. Measurement of race and ethnicity in a changing, multicultural America. Race and Social Problems, 1(3), 111.

Iceland, J., 2004. Beyond Black and White metropolitan residential segregation in multi-ethnic America. Social Science Research, 33, 248-271.

Iceland, J., Weinberg, D., and Steinmetz, E., 2002. Racial and Ethnic Residential Segregation in the United States: 1980-2000.

Kimerling, A.J., 2009. Dotting the dot map, revisited. Cartography and Geographic Information Science, 36(2), 165-182.

Krieger, N., 2006. A century of census tracts: health \& the body politic (1906-2006). Journal of urban health, 83(3), 355-361.

Laidlaw, W., 1906. Federation districts and a suggestion for a convenient and scientific city map system. Federation, 4, 1-6.

Langford, M. and Unwin, D.J., 1994. Generating and mapping population density surfaces within a geographical information system. The Cartographic Journal, 31(1), 21-26.

Lee, S.M., 1993. Racial classifications in the US census: 1890-1990. Ethnic and racial studies, 16(1), 75-94.

Logan, J.R., et al., 2004. Segregation of minorities in the metropolis: Two decades of change. Demography, 41(1), 1-22.

Manson, S., et al., 2019. IPUMS National Historical Geographic Information System: Version 14.0 [Database]. Minneapolis, MN: IPUMS.

Massey, D.S. and Denton, N.A., 1987. Trends in the residential segregation of Blacks, Hispanics, and Asians: 1970-1980. American sociological review, 802-825.

Mennis, J., 2003. Generating surface models of population using dasymetric mapping. The Professional Geographer, 55(1), 31-42.

Nobles, M., 2000. History counts: a comparative analysis of racial/color categorization in US 
and Brazilian censuses. American Journal of Public Health, 90(11), 1738.

Owens, B.R., 2012. Mapping the city: Innovation and continuity in the Chicago School of Sociology, 1920-1934. The American Sociologist, 43 (3), 264-293.

Palmer, V., 1929. The study of the growth of local communities of Chicago.

Parisi, D., Lichter, D.T., and Taquino, M.C., 2011. Multi-scale residential segregation: Black exceptionalism and America's changing color line. Social Forces, 89(3), 829-852.

Park, R.E. and Burgess, E.W., 2019. The city. University of Chicago Press.

Perc, M., 2014. The Matthew effect in empirical data. Journal of The Royal Society Interface, 11,20140378

Petrov, A., 2012. One hundred years of dasymetric mapping: back to the origin. The Cartographic Journal, 49(3), 256-264.

Prener, C.G. and Revord, C.K., 2019. areal: An R package for areal weighted interpolation. Journal of Open Source Software, 4(37), 1221.

Rabinowitz, H.N., et al., 1978. Race relations in the urban south, 1865-1890. Oxford University Press.

Radford, J.P., 1976. Race, residence and ideology: Charleston, South Carolina in the midnineteenth century. Journal of Historical Geography, 2 (4), 329-346.

Roth, R.E., 2010. Dot density maps. The Encyclopedia of Geography, 787-790.

Snipp, C.M., 2003. Racial measurement in the American census: Past practices and implications for the future. Annual Review of Sociology, 29 (1), 563-588.

Stepinski, T.F. and Dmowska, A., 2020. Complexity in patterns of racial segregation. Chaos, Solitons 83 Fractals, 140, 110207.

Theil, H. and Finizza, A.J., 1971. A Note on the Measurement of Racial Integration of Schools by Means of Informational Concepts. The Journal of Mathematical Sociology, 1(2), 187-193.

White, M.J., 1988. American neighborhoods and residential differentiation. Russell Sage Foundation.

Wright, J.K., 1936. A method of mapping densities of population: With Cape Cod as an example. Geographical Review, 26(1), 103-110.

Wright, R., et al., 2014. Patterns of racial diversity and segregation in the United States: 1990-2010. The Professional Geographer, 66(2), 173-182.

Yao, J., et al., 2018. Spatial segregation measures: A methodological review. Tijdschrift voor economische en sociale geografie, 110(3), 235-250. 